\title{
Life-cycle greenhouse gas inventory analysis of household waste management and food waste reduction activities in Kyoto, Japan
}

\section{$\operatorname{AUTHOR}(\mathrm{S})$ :}

Matsuda, Takeshi; Yano, Junya; Hirai, Yasuhiro; Sakai, Shin-ichi

\section{CITATION:}

Matsuda, Takeshi ... [et al]. Life-cycle greenhouse gas inventory analysis of household waste management and food waste reduction activities in Kyoto, Japan. The International Journal of Life Cycle Assessment 2012, 17(6): 743-752

ISSUE DATE:

2012-07

URL:

http://hdl.handle.net/2433/159941

\section{RIGHT:}

(C) The Author(s) 2012. This article is published with open access at Springerlink.com 
Life-cycle greenhouse gas inventory analysis of household waste management and food waste reduction activities in Kyoto, Japan

\section{Takeshi Matsuda, Junya Yano, Yasuhiro Hirai \& Shin-ichi Sakai}

The International Journal of Life Cycle Assessment

ISSN 0948-3349

Volume 17

Number 6

Int J Life Cycle Assess (2012) 17:743-752 DOI 10.1007/s11367-012-0400-4

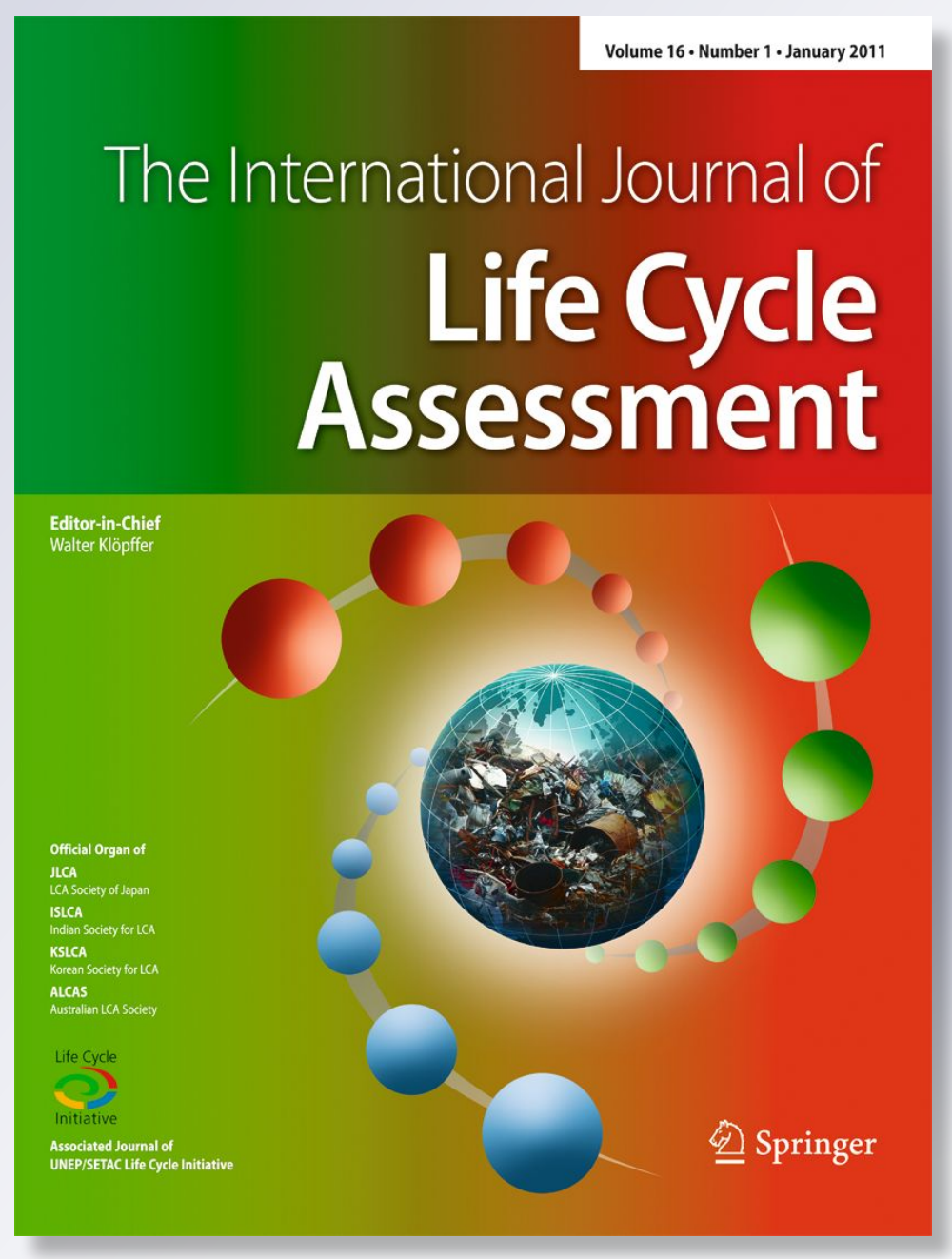

包 Springer 
Your article is published under the Creative Commons Attribution license which allows users to read, copy, distribute and make derivative works, as long as the author of the original work is cited. You may selfarchive this article on your own website, an institutional repository or funder's repository and make it publicly available immediately. 


\title{
Life-cycle greenhouse gas inventory analysis of household waste management and food waste reduction activities in Kyoto, Japan
}

\author{
Takeshi Matsuda • Junya Yano • Yasuhiro Hirai • \\ Shin-ichi Sakai
}

Received: 28 February 2011 / Accepted: 22 February 2012 / Published online: 3 April 2012

(C) The Author(s) 2012. This article is published with open access at Springerlink.com

\begin{abstract}
Purpose Source-separated collection of food waste has been reported to reduce the amount of household waste in several cities including Kyoto, Japan. Food waste can be reduced by various activities including preventing edible food loss, draining moisture, and home composting. These activities have different potentials for greenhouse gas (GHG) reduction. Therefore, we conducted a life-cycle inventory analysis of household waste management scenarios for Kyoto with a special emphasis on food waste reduction activities.

Methods The primary functional unit of our study was "annual management of household combustible waste in Kyoto, Japan." Although some life-cycle assessment scenarios included food waste reduction measures, all of the scenarios had an identical secondary functional unit, "annual food ingestion (mass and composition) by the residents of Kyoto, Japan." We analyzed a typical incineration scenario (Inc) and two anaerobic digestion (dry thermophilic facilities) scenarios involving either source-separated collection (SepBio) or nonseparated collection followed by mechanical sorting (MecBio). We assumed that the biogas from anaerobic digestion was used for power generation. In addition, to evaluate the effects of waste reduction combined with separate collection, three food waste reduction cases were considered in the SepBio scenario: (1) preventing loss of edible food (PrevLoss);
\end{abstract}

Responsible editor: Shabbir Gheewala

Electronic supplementary material The online version of this article (doi:10.1007/s11367-012-0400-4) contains supplementary material, which is available to authorized users.

T. Matsuda $\cdot$ J. Yano $\cdot$ Y. Hirai $(\bowtie) \cdot$ S. Sakai Environmental Preservation Research Center, Kyoto University,

Yoshida-honmachi, Sakyo-ku Kyoto, Kyoto 606-8501, Japan

e-mail: hirai@eprc.kyoto-u.ac.jp
(2) draining moisture contents (ReducDrain); and (3) home composting (ReducHcom). In these three cases, we assumed that the household waste was reduced by $5 \%$.

Results and discussion The GHG emissions from the Inc, MecBio, and SepBio scenarios were 123.3, 119.5, and 118.6 $\mathrm{Gg} \mathrm{CO}_{2}$-eq/year, respectively. Compared with the SepBio scenario without food waste reduction, the PrevLoss and ReducDrain cases reduced the GHG emissions by 17.1 and $0.5 \mathrm{Gg} \mathrm{CO}_{2}$-eq/year. In contrast, the ReducHcom case increased the $\mathrm{GHG}$ emissions by $2.1 \mathrm{Gg} \mathrm{CO}_{2}$-eq/year. This is because the biogas power production decreased due to the reduction in food waste, while the electricity consumption increased in response to home composting. Sensitivity analyses revealed that a reduction of only $1 \%$ of the household waste by food loss prevention has the same GHG reduction effect as a 31 -point increase (from $50 \%$ to $81 \%$ ) in the food waste separation rate.

Conclusions We found that prevention of food losses enhanced by separate collection led to a significant reduction in GHG emissions. These findings will be useful in future studies designed to develop strategies for further reductions in GHG emissions.

Keywords Anaerobic digestion - Food loss prevention . Food waste - Greenhouse gas emissions · Household waste . Life-cycle inventory Waste reduction activities

\section{Introduction}

Recycling of biodegradable waste has attracted much interest from governments and researchers worldwide as a means of reducing greenhouse gas (GHG) emissions. A number of countries around the world (e.g., South Korea, European countries) have incorporated biodegradable waste recycling 
into their waste management systems (European Commission 2008; Kim and Kim 2010). In Japan, 220 out of 1800 Japanese local governments implement separate collection of household food waste, although incineration is still a common practice for food waste disposal (MOE, Japan 2008). Several studies have included life-cycle assessment and cost-benefit analysis of biodegradable waste recycling schemes (Eriksson et al. 2005; European Commission 2010; Fukushima et al. 2008; Sonesson et al. 2000; Sakai et al. 2005; Inaba et al. 2010). Sonesson et al. (2000) developed the ORWARE software to evaluate the environmental burdens associated with waste treatment processes such as incineration, composting, and anaerobic digestion. Eriksson et al. (2005) compared the environmental impacts of several waste management scenarios using ORWARE and concluded that anaerobic digestion reduces more GHG emissions than other treatment methods such as incineration and controlled landfilling. These findings are consistent with the results of other studies (European Commission 2010; Fukushima et al. 2008; Sakai et al. 2005; Inaba et al. 2010).

There are two methods to separate biodegradable waste for biological treatment: source-separated collection and nonseparated collection followed by mechanical sorting [commonly referred to as mechanical biological treatment (MBT)]. MBT has been developed and used in European countries (European Commission 2008). Although there are no MBT facilities in Japan, similar technologies have been developed to separate food and paper waste from mixed household waste (Asano et al. 2005; Takuma 2005; Tatara et al. 2010). Whereas nonseparated collection coupled with mechanical sorting has little impact on household waste disposal behavior, sourceseparated collection has been reported to reduce food waste by changing the household behavior (WRAP 2009; European Commission 2010). The decision-making model proposed by Hirose (1995) can be used to explain such a change in behavior to a form that is more environmentally friendly. The presence of source-separated collection encourages waste generators to visualize the amount of food waste for each household, which in turn stimulates the perception of seriousness, perception of responsibility, and evaluation of feasibility, thereby promoting food waste reduction (Fig. 1). The prevention of edible food waste, termed food loss, is important from the viewpoint of its associated reduced environmental impact (WRAP 2009; Davis and Sonesson 2008; Cuellar and Webber 2010).

In general, waste reduction leads to reductions of both the environmental burden and the amount of recyclables. If recycling is very effective and the life-cycle environmental impact of waste is negative, then the reduction in waste may be environmentally undesirable. Conversely, if recycling of waste is not effective, then waste reduction will be environmentally desirable. Thus, the benefit of waste reduction and the cost of reduced recyclables must be quantified to evaluate the total outcome of waste reduction measures.

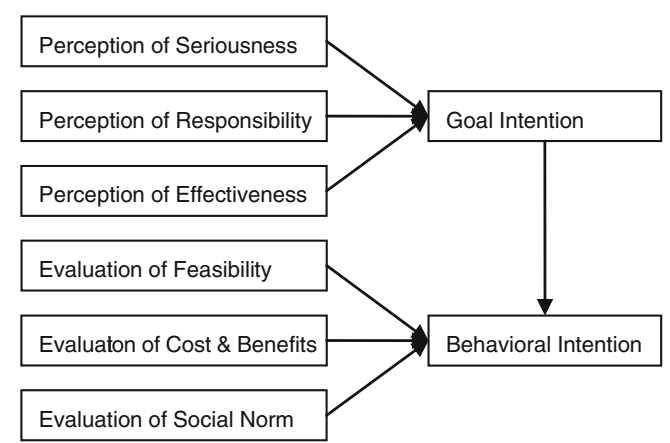

Fig. 1 Decision-making model of environmentally friendly behavior (Hirose 1995)

Matsuda et al. (2010a, b) studied this tradeoff between anaerobic digestion and the prevention of food loss and concluded that even if anaerobic digestion were implemented, the reduction in GHG as a result of decreased food production would outweigh the reduction of recyclable food waste. The European Commission (2010) assumed that the introduction of separate collection of biowaste would decrease household biowaste by $7.5 \%$ as of 2020 , mainly via food loss prevention; therefore, the commission analyzed the environmental and financial impact of widespread separate collection. The results of this study indicated that GHG reduction via food loss prevention in European Union countries could be three or four times higher than the reduction in response to separate collection without waste prevention. However, these two studies only considered food loss prevention, whereas other activities, such as water draining and home composting, can also reduce food waste. Accordingly, these latter activities should be taken into account to better understand the impact of separate collection of food waste.

In this study, we conducted a life-cycle inventory (LCI) analysis of household waste management by incineration and anaerobic digestion. Regional composting is not discussed here because it is not feasible in metropolitan areas like Kyoto due to the lack of local demand for the compost. Our LCI analysis compared two methods for separating food and paper waste from mixed household waste: source-separated collection and nonseparated collection followed by mechanical sorting. Finally, we analyzed three food waste reduction activities: food loss prevention, water draining, and home composting.

\section{Methods}

\subsection{Functional units}

Cleary (2010) proposed an approach known as waste management and prevention life-cycle assessment (LCA; 
WasteMAP LCA) to evaluate the environmental impact of recycling as well as waste prevention. Following this approach, we set two functional units: a primary functional unit for waste management and a secondary functional unit for waste prevention. The primary functional unit of our study was the annual management of household combustible waste in Kyoto, Japan. Although some of the LCA scenarios included food waste reduction measures, all of the scenarios had an identical secondary functional unit, the annual food ingestion (mass and composition) by the residents of Kyoto, Japan.

The amount of household combustible waste is shown in Table 1 (Matsuda et al. 2010b; Kyoto City Environmental Policy Bureau 2009a, b). Here, combustible waste does not include directly landfilled waste or already recycled waste, such as newspapers. To best represent differences in collection rates for recycling, we divided paper waste into four categories: recyclable paper, paper packaging, disposable diapers, and other papers. Newspaper, cardboard, and similar papers can be recycled back to paper; therefore, we refer to them collectively as recyclable paper for the purposes of this discussion. Other papers such as used tissue paper are especially difficult to recycle. In this study, only unrecyclable types of paper such as disposable diapers and other papers are the source separation targets.

\subsection{Scenario setting}

We studied the three waste management scenarios shown in Fig. 2 to evaluate the effects of recycling. The incineration scenario (Inc) represents the current waste management system in Kyoto for fiscal year 2008 (April 2008 to March 2009). In this scenario, the incineration facility recovers energy from waste in the form of electricity, but not heat. In the second scenario (SepBio), food and paper waste are separated at home, collected and sent to the facility, where they are digested anaerobically. We assume here that the wastes are treated by dry thermophilic anaerobic digestion. We also assume that the biogas from the anaerobic digestion is used to generate power and heat the methane fermenter, but not to supply heat outside the facility (e.g., district heating). The third scenario (MecBio) involves mechanical sorting of mixed household wastes at treatment facilities. Sorted wastes are then digested as in the SepBio scenario. In both the SepBio and the MecBio scenarios, the rest of the combustible waste is incinerated. We assumed that the amounts of the combustible waste to be treated in these three basic scenarios were the same (see Table 1).

In addition, we studied three waste reduction cases using SepBio as the baseline scenario. In the PrevLoss case, food waste is reduced by food loss prevention. In the ReducDrain case, waste reduction is achieved via

Table 1 Household waste ${ }^{\mathrm{a}}$ generation in Kyoto, ${ }^{\mathrm{b}}$ FY 2008 (from April 2008 to March 2009)

\begin{tabular}{|c|c|c|c|c|c|}
\hline \multirow[t]{2}{*}{ Waste categories } & \multirow[t]{2}{*}{ Subcategories } & \multirow[t]{2}{*}{ No reduction } & \multicolumn{3}{|c|}{ Waste reduction cases ${ }^{\mathrm{c}}$} \\
\hline & & & PrevLoss & ReducDrain & ReducHcom \\
\hline \multirow[t]{4}{*}{ Food } & Cooking waste & 42,369 & 42,369 & 36,702 & 36,702 \\
\hline & Leftovers & 17,305 & 10,932 & 14,990 & 14,990 \\
\hline & Untouched food & 12,087 & 7,636 & 10,471 & 10,471 \\
\hline & Tea leaves and coffee residues & 9,168 & 9,168 & 7,942 & 7,942 \\
\hline \multirow[t]{4}{*}{ Paper } & Recyclable papers & 17,040 & 17,040 & 17,040 & 17,040 \\
\hline & Paper packaging & 13,960 & 13,960 & 13,960 & 13,960 \\
\hline & Disposable diapers & 6,702 & 6,702 & 6,702 & 6,702 \\
\hline & Other papers & 29,379 & 29,379 & 29,379 & 29,379 \\
\hline Plastics & & 28,300 & 28,300 & 28,300 & 28,300 \\
\hline Wood and grasses ${ }^{\mathrm{d}}$ & & 9,447 & 9,447 & 9,447 & 9,447 \\
\hline Other & & 30,733 & 30,733 & 30,733 & 30,733 \\
\hline Total & & 216,490 & 205,666 & 205,666 & 205,666 \\
\hline \multirow[t]{3}{*}{ Component (\%wet) } & Water & 41.3 & 39.7 & 38.2 & 39.6 \\
\hline & VS & 49.1 & 50.2 & 51.7 & 50.5 \\
\hline & Ash & 9.6 & 10.0 & 10.1 & 9.9 \\
\hline
\end{tabular}

\footnotetext{
${ }^{\text {a }}$ Data are expressed as tons wet waste/year

${ }^{\mathrm{b}}$ In 2008, the population of Kyoto was $1,464,990$

${ }^{\mathrm{c}}$ Data in bold font indicates waste reduction

${ }^{\mathrm{d}}$ Wood and grasses are wastes composed of wood or grasses (e.g., garden waste, packaging and containers made of wood, furniture made of wood)
} 
water-draining methods such as the use of an outlet drain net or a sink corner strainer. In the ReducHcom case, food waste is reduced by home composting. In these three cases, we assumed that the amount of combustible waste would be reduced by $5 \%$. In addition, we conducted a sensitivity analysis of the waste reduction rate to address the uncertainty associated with this parameter. The default assumption is based on our previous investigation of source-separated collection of food and paper waste in Kyoto from October 2008 to September 2009 (Matsuda et al. 2010b). In this previous study, we carried out questionnaire surveys regarding household disposal behavior and found that participants in the separate collection of food waste developed waste reduction behaviors such as food loss prevention and water draining. However, we did not have enough information to estimate the contribution of each waste reduction activity to the total $5 \%$ reduction in combustible waste. Thus, instead of analyzing one representative reduction case with mixed reduction activities, we compared three hypothetical waste reduction cases that each addressed one reduction activity.

The amounts of combustible waste for the three cases are shown in Table 1. To better represent the different reduction patterns of food waste among the three cases, we divided the food waste into four categories: cooking waste, leftovers, untouched food, and tea leaves and coffee residues. Here, cooking waste refers to the food waste generated during processing and preparation of meals such as fish bones and vegetable skins. In the PrevLoss case, only the food loss associated with leftovers and untouched food is reduced. In Kyoto, $37.4 \%$ of household combustible waste was food waste, of which $36.3 \%$ was food losses. Thus, food loss constitutes $13.6 \%(0.374 \times 0.363)$ of the household combustible waste. Therefore, a $5 \%$ reduction in the combustible waste is equivalent to a $13.4 \%(0.05 / 0.374)$ reduction of food waste and $36.8 \%(0.05 / 0.136)$ reduction in food losses. We assumed that this reduction of food loss is achieved by reduced food production via constant food ingestion (i.e., not by constant food production with increased food ingestion). In the ReducDrain case, we assumed that the moisture content of the food waste was reduced from $77 \%$ to $73 \%$, which is equivalent to a $13.4 \%$ reduction in food waste and a $5 \%$ reduction in combustible waste. In the ReducHcom case, we assumed that $13.4 \%$ of the food waste, or $5 \%$ of the combustible waste, is composted at home. The amounts of the food waste for the ReducDrain and ReducHcom cases were the same except for their moisture contents.

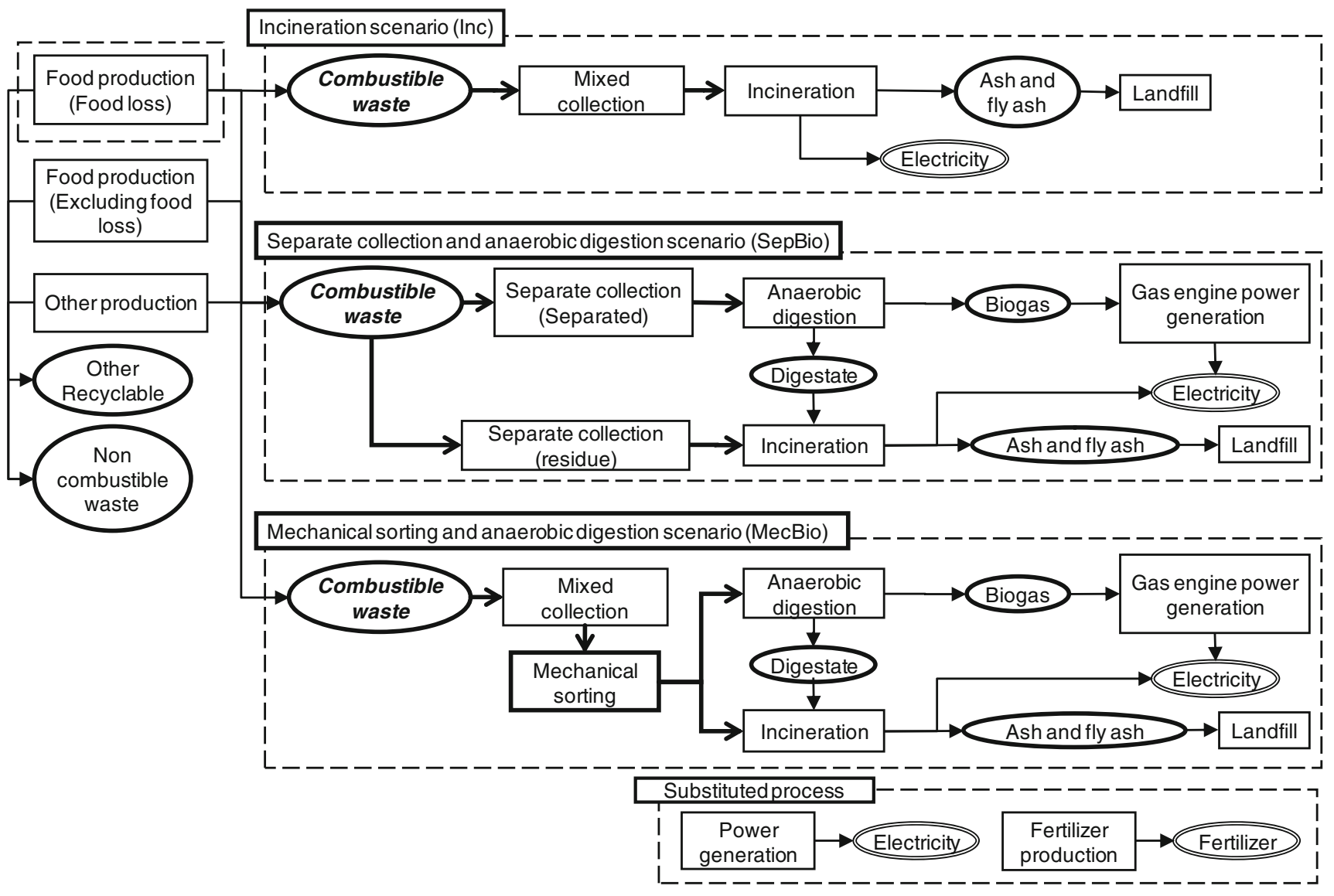

Fig. 2 System boundary and flow diagram 


\subsection{System boundary}

Figure 2 shows the system boundaries and the waste streams in this study. The food production process only depicts household food losses, i.e., food production processes for food ingested. All electricity generated from waste and biogas is transmitted through the power grids and replaces commercial electricity from utility companies, but is not used directly by the waste treatment facilities themselves. Compost substitutes for chemical fertilizer with the same amount of nitrogen. Construction, demolition, and final disposal of capital equipment were not considered in this study because they are relatively small (Matsuto et al. 2001). Thus, we decided to focus on the operating phase. In the ReducDrain case, wastewater from the kitchen would increase slightly; however, we did not consider the additional burden to waste water treatment because our preliminary assessment indicated that it made a small contribution to the total GHG emissions in the system being analyzed.

\subsection{Impact category}

Climate change was the only impact category considered for this study. In the 1990s, the major issues associated with waste management in Japan were landfill consumption and dioxin emissions; however, these have been intensively addressed over the past 20 years. In fact, the annual landfill consumption in Japan has decreased from 106 million tons/ year in 1990 to 22 million tons/year in 2008 (Ministry of Environment 2011), and the dioxin emissions from waste incineration have decreased from $7200 \mathrm{~g}$ TEQ/year in 1997 to $100 \mathrm{~g} \mathrm{TEQ} /$ year in 2009 (Ministry of Environment 2011). However, GHG emissions from the waste management sector in Japan have decreased only slightly, from $25.6 \mathrm{Tg}$ $\mathrm{CO}_{2}$-eq/year in 1990 to $21.8 \mathrm{Tg} \mathrm{CO}$-eq/year in 2009 (GIO National Institute for Environmental Studies 2011). Thus, the authors believe that GHG emissions have become the most important environmental aspect for waste management in Japan. In addition, several environmental impact categories (e.g., acidification, smog formation) that are associated with emissions from thermal processes are generally strongly correlated with GHG emissions. This correlation suggests that GHG emissions could be used as a proxy indicator for the impact categories mentioned above.

It should be noted that the limited scope of the impact categories has some drawbacks. For example, nutrient emissions that lead to eutrophication were identified as an important impact category for food production processes (Davis and Sonesson 2008). However, the nutrient emissions are not strongly related to thermal processes, which invalidates the potential for use of GHG emissions as a proxy indicator. Despite these drawbacks, we focused on
GHG emissions in this study. We will address the aforementioned drawbacks in future studies.

\subsection{Unit processes}

In the food production process, we used calculated values (Matsuda et al. 2010a) to determine the GHG emissions from agricultural production, fishery activities, and processing and transportation of foods. Additionally, the emissions assigned to the leftovers included energy consumption for home cooking. It was assumed that all foods were grown and processed in Japan. This assumption is likely to underestimate the GHG emissions because the energy consumption for importing is not accounted for. Accordingly, the reduction in GHG emissions in the PrevLoss case might be underestimated.

In the collection process, we assumed that, in the separated collection scenarios (SepBio, PrevLoss, ReducDrain, ReducHcom), the separated waste and other combustible waste were each collected twice a week on different days. We also assumed that, in the nonseparated collection scenarios (Inc, MecBio), the combustible waste was collected twice a week. These assumptions are based on a separate collection experiment performed in Kyoto (Matsuda et al. 2010b). In the SepBio scenario, we applied the observed separation rates (Matsuda et al. 2010b) as the default values for these parameters. These data are listed in the Electronic Supplementary Material 1. We conducted a sensitivity analysis of the separation rate for the food waste to address the uncertainty associated with this parameter.

In the transport processes (expressed as arrows in Fig. 2), the average distance from the street side stations to the treatment facilities was $19 \mathrm{~km}$, while that from the incineration facility to the landfill site was $50 \mathrm{~km}$. These distances were based on actual geographical data for Kyoto.

In the mechanical sorting process, we applied published values for the sorting rates (Takuma 2005; see the Electronic Supplementary Material 1).

In the incineration process, electrical power consumption for the incinerator was calculated using an empirical formula (NIES 2008) based on waste composition. The $\mathrm{CO}_{2}$ emissions associated with the combustion of each waste type were calculated using the elemental composition of the waste. Here, the carbon content of the biogenic waste produced by photosynthesis originates from the $\mathrm{CO}_{2}$ in the atmosphere. Thus, $\mathrm{CO}_{2}$ emissions from the biogenic waste were assumed to be carbon neutral and their net $\mathrm{CO}_{2}$ emissions were considered to be zero. This accounting method was also applied to combustion of the biogas.

In the anaerobic digestion process, the biogas production was calculated based on the observed values in a pilot-scale study of Kyoto. Energy consumption in the anaerobic digestion facility was assumed to depend on the dry mass of 
the waste, because water is routinely added to the digestion reactor so that the water content of the waste remains constant. The digestate was incinerated in the incineration process.

In the landfill process, energy consumption for leachate treatment was calculated. We assumed that there were no landfill gas emissions, because only incineration residues with very low carbon content were landfilled in this study.

The home composting process was based on Tabata et al. (2009). We assumed that $10 \%$ of households used electric drying machines for composting, while the remaining $90 \%$ used nonelectric composters.

The global warming potentials of methane and nitrous oxide for this study were 25 and 298, respectively (IPCC 2007). Other parameters used in this study and some formulas are shown in the Electronic Supplementary Material 2 and 3 (Matsuda et al. 2010a; Murata 2000; NIES 2006; Tabata et al. 2009; Takuma 2005).

\section{Results}

Figure 3 presents the GHG emissions from the three scenarios. Anaerobic digestion with separated collection (SepBio) was found to reduce $\mathrm{GHG}$ by $4.70 \mathrm{Gg} \mathrm{CO}_{2}$-eq/year when compared with the incineration (Inc) scenario. Mechanical sorting and anaerobic digestion (MecBio) reduced GHG by $3.81 \mathrm{Gg} \mathrm{CO}_{2}$-eq/year. The separation rate of the mechanical sorting is higher than that of the source separation in the SepBio scenario, enabling more power generation. However, MecBio consumes more energy during sorting of the mixed waste and treatment of nonbiodegradable waste than the separate collection does. Thus, the MecBio scenario was

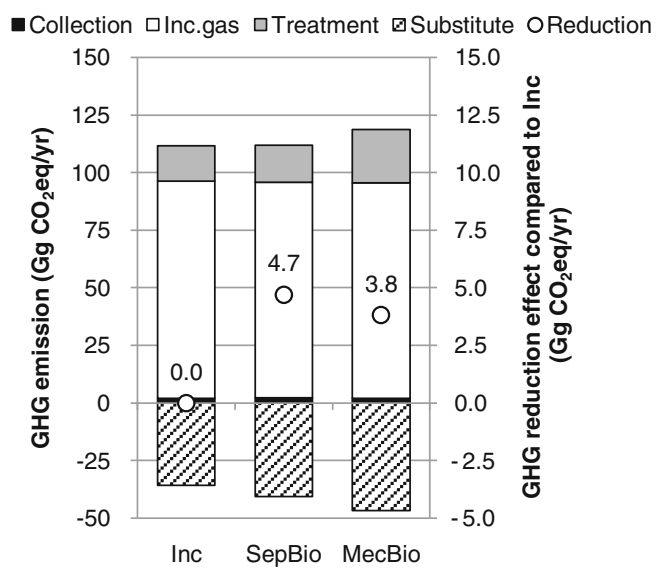

Fig. 3 GHG emissions from the three waste treatment scenarios. The GHG emissions are divided into four processes: Collection, Inc. gas, Treatment, and Substitution. Inc. gas represents $\mathrm{CO}_{2}$ emissions from the incineration of fossil fuel products in the waste. Reduction (white rectangles) indicate the GHG reduction compared to the Inc. gas scenario

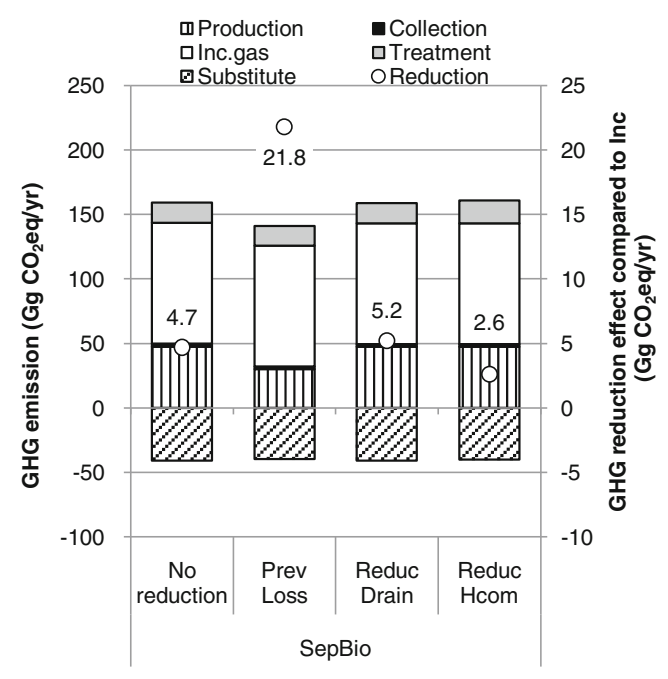

Fig. 4 GHG emissions from the separated collection (SepBio) scenario and the three waste reduction cases. Production indicates the GHG emissions from production, distribution, and cooking for the food losses. Reduction (white rectangles) indicate the GHG reduction compared to the Inc. gas scenario

less favorable than the SepBio scenario with respect to GHG emissions.

Figure 4 shows the results for the waste reduction cases. The GHG emissions for food losses in Kyoto were estimated to be $46.8 \mathrm{Gg} \mathrm{CO}_{2}$-eq/year. The $\mathrm{GHG}$ emissions were reduced by $21.5 \mathrm{Gg} \mathrm{CO}_{2}$-eq/year in the PrevLoss case when compared to the Inc scenario. This reduction is more than four times larger than that of the SepBio scenario. In contrast, the GHG reduction in response to the ReducDrain case was almost the same as that for the SepBio scenario. This was because only the moisture content of the food waste was reduced, while the dry mass remained the same in the ReducDrain case. The energy consumption in the anaerobic digestion facility depends on the dry mass of the waste in our model; thus, the energy consumption is virtually unchanged. Finally, in the ReducHcom case, the GHG emissions increased by $2.60 \mathrm{Gg} \mathrm{CO}_{2}$-eq/year when compared to the SepBio scenario. This was because the biogas production was reduced while the energy consumption was increased by the electric home composters. In addition, the reduction of GHG emissions by replacing chemical fertilizers with compost in the ReducHcom case was much less than that by the use of anaerobic digestion.

\section{Discussion}

\subsection{Sensitivity analysis}

We conducted two sensitivity analyses to check the stability of the results and compare the relative importance of the separation rate and the waste reduction rate. 


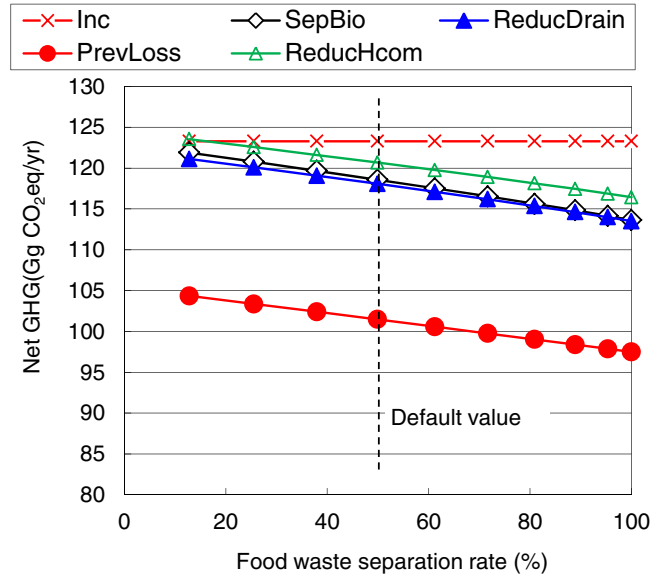

Fig. 5 Sensitivity analysis of food waste source separation rate

First, the sensitivity to the source separation rate was calculated (Fig. 5). To accomplish this, we fixed the separation rate for the paper waste at the default value and varied the separation rate for the food waste between $10 \%$ and $100 \%$. The results showed that, even if all food waste was collected separately, the GHG reduction of the food losses prevention (PrevLoss) scenario was higher than that of the source-separated collection followed by biogasification without food waste reduction (SepBio).

Second, the sensitivity to the household waste reduction rate was calculated (Fig. 6). We varied the reduction rate of the household combustible waste from $0 \%$ to $10 \%$, which corresponds to $0 \%$ to $27.0 \%$ of the food waste and $0 \%$ to $73.5 \%$ of the food loss. When the household waste was reduced by $10 \%$, the GHG reduction of the PrevLoss, PrevDrain and PrevHcom cases was $34.2 \mathrm{Gg} \mathrm{CO}_{2}$-eq/year, 1.0 $\mathrm{Gg} \mathrm{CO}_{2}$-eq/year, and $-4.2 \mathrm{Gg} \mathrm{CO}_{2}$-eq/year, respectively.

Next, we used these results to assess the impact of uncertainty regarding the relative contributions of the three waste reduction activities. To accomplish this, we fixed the sum of the waste reduction rates at $5 \%$, changed the contributions from the three activities, and calculated the GHG

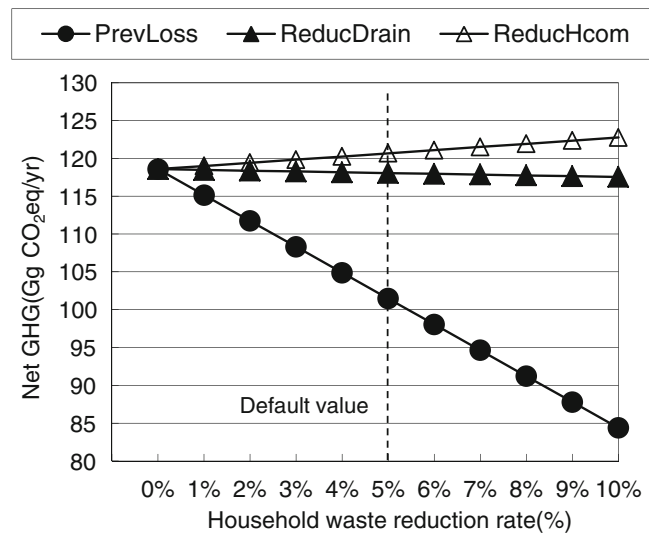

Fig. 6 Sensitivity analysis of waste reduction rate reduction. The results are shown in a ternary contour graph (Fig. 7). The area within the triangle represents all possible combinations of the three activities that result in a total waste reduction of 5\% (PrevLoss + ReducDrain + ReducHcom $=5 \%$ ). The results show that GHG emissions will be reduced if the prevention of food loss accounts for more than one tenth of the total waste reduction by the three activities.

Comparison of Figs. 5 and 6 revealed that a reduction of only $1 \%$ of the household waste by food loss prevention has the same GHG reduction effect as a 31-point increase (from $50 \%$ to $81 \%$ ) in the food waste separation rate. This comparison shows that a precise estimation of the food loss prevention rate is more important than that of the food waste separation rate to refine the estimated GHG reduction for the entire lifecycle of the source-separated collection systems.

\subsection{Comparison with previous studies}

We compared the results for the three waste management scenarios without waste reduction with those of previous studies. When the unit of the life-cycle GHG emissions was converted to per ton of waste, the results of the Inc, SepBio, and MecBio scenarios became $566 \mathrm{~kg} \mathrm{CO}$-eq/t waste, $545 \mathrm{~kg} \mathrm{CO}$-eq/t waste, and $549 \mathrm{~kg} \mathrm{CO}_{2}$-eq/t waste, respectively. Eriksson et al. (2005) demonstrated that the GHG emissions from the incineration of municipal solid waste were $855 \mathrm{~kg} \mathrm{CO}$-eq/t waste, while those from anaerobic digestion were $793 \mathrm{~kg} \mathrm{CO}_{2}$-eq/t waste. Inaba et al. (2010) reported that $331 \mathrm{~kg} \mathrm{CO}$-eq/t waste were emitted in the incineration scenario, while $325 \mathrm{~kg} \mathrm{CO}$-eq/t waste were

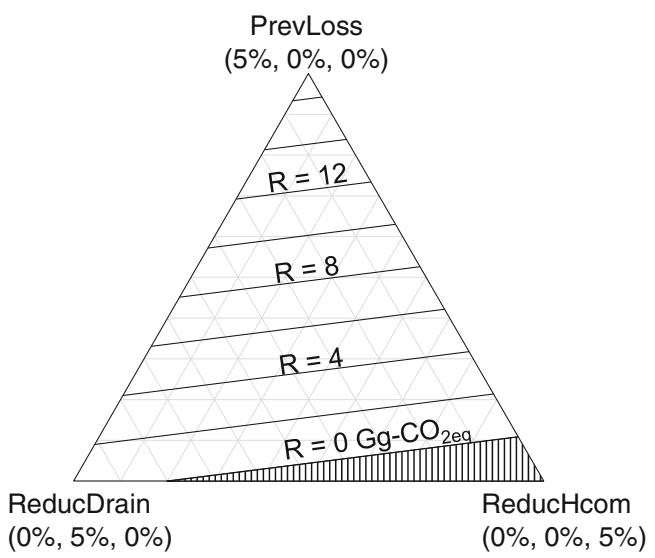

Fig. 7 Reduction of GHG emissions in response to combinations of waste reduction activities: prevention of food loss (PrevLoss), draining of water (ReducDrain), and home composting (ReducHcom). The sum of the waste reduction rates in response to the three activities is fixed at $5 \%$. Each of the three apexes of the ternary graph represents a situation in which only one of the three activities is practiced. The contour lines represent the level of GHG reductions. The shaded area shows the conditions under which the waste reduction will increase the GHG emissions 
emitted in the anaerobic digestion scenario. Our results are consistent with those of previous studies in that the GHG emissions from the anaerobic digestion scenarios are lower than those from the incineration scenarios. The differences in the absolute emission levels among these studies are likely a result of differences in the system boundaries, waste composition, and separation rates among studies.

It is important to discuss the units of the GHG emissions. Specifically, the use of $\mathrm{kg} \mathrm{CO}_{2}$-eq/t should be avoided in favor of $\mathrm{kg} \mathrm{CO}_{2}$-eq/(person-year) in comparisons among several waste prevention scenarios from different studies, because the denominator of the former is affected by waste prevention while that of the latter is not. In waste prevention cases, the GHG emissions and amounts of waste are different from the reference scenario. In fact, a waste prevention case with lower GHG emissions than the reference scenario may result in higher GHG emissions per ton of waste than the default scenario (e.g., a case with $50 \%$ waste reduction and $40 \%$ GHG reduction will result in $120 \%(=60 / 50)$ of the reference GHG emissions per ton of waste).

\subsection{Limitations}

It should be noted that this study has the following limitations:

1. Only the GHG emissions are addressed.

2. There is great uncertainty associated with the waste reduction rate.

3. Contributions of the three reduction activities to the waste reduction are unknown.

4. Food loss prevention is assumed to be achieved by decreased production of food, not by increased ingestion of food.

Regarding the first limitation, previous studies have suggested the importance of nutrient emissions from food production processes. If we had included this impact category, the results would have reemphasized the importance of food loss prevention. Accordingly, the scope of the impact categories should be expanded to confirm the robustness of our results. Regarding the second limitation, our sensitivity analysis showed that even when the waste reduction rate is small, we can expect a large GHG reduction from the food loss prevention. Regarding the third limitation, our results showed that the three waste reduction activities have different effects on the GHG emissions, which suggests the importance of quantitative estimates to the contribution of each waste reduction activity. This point is one of the central targets of our ongoing research. The fourth limitation can be addressed in part by adding one more case, food loss prevention by increased ingestion. The results for this case would fall between those of the PrevLoss case and the ReducDrain case, suggesting that, from the viewpoint of global warming, food loss prevention is better achieved by decreased food production than increased ingestion.

\subsection{Implications}

Our results have two implications. First, it is necessary to advance the methods used for measuring changes in the disposal/consumption behavior of residents to quantify the impact of source-separated collection. Second, local authorities should expand the system boundaries for their strategic environmental assessment beyond waste treatment processes.

With respect to the first implication, precise estimations of the food waste separation rate and the waste reduction rate are important to better understand the impact of sourceseparated collection. In addition, contributions to the waste reduction from food loss prevention, draining, and home composting should be quantified. However, the waste reduction rate and the contribution of each activity are currently difficult to measure.

Measurement of the waste reduction rate is possible by comparing the amount of waste before and after introduction of source-separated collection. However, the effects of the source-separated collection should be distinguished from other factors such as annual fluctuations and long-term trends. Moreover, it is not easy to apply this method to elucidate the current reduction levels in municipalities in which source-separated collection has long been employed. To improve this estimation, accumulation of the empirical data and meta-analysis of these data would be useful. Panel data analysis might be especially useful for revealing the average waste reduction rate as well as the effects of different policy measures among local governments (e.g., collection frequency for the combustible waste) on the waste reduction rate. This type of empirical analysis has been widely applied to the pay-as-you-throw system (Miranda and Aldy 1998; Kinnaman and Fullerton 2000; Usui 2008). Accordingly, a similar approach to the separate collection system is warranted.

The measurement of the contribution of each waste reduction activity is more difficult. It is theoretically possible to determine the contributions of the three activities by developing a linear equations system that describes the changes in moisture content, food loss, and total food waste using three unknown parameters for the levels of the three waste reduction activities (see Electronic Supplementary Material 4). However, the estimates obtained by this method would likely be imprecise due to measurement errors during the waste composition analysis. To address the measurement error problem, estimation based on information sources other than the waste mass and waste composition would be useful. For example, surveys of the usage patterns of composters would enable quantification of the amount of home composting. A household expenditure survey might be a useful source for 
estimating changes in the amount of food purchased. Furthermore, this issue is not limited to food waste prevention. For example, reduction of plastic bottle waste will be achieved by weight saving, tumbler usage, and reduced consumption. Sharp et al. (2010) reviewed several methods for measuring the waste prevention effect and recommended combinations of these methods.

Regarding the second implication, our results confirmed the importance of the food production phase to the evaluation of food waste management systems. Thus, expansion of system boundaries beyond the waste treatment processes is inevitable. The US EPA (2010) developed the Waste Reduction Model to help solid waste planners calculate reductions in GHG emissions in response to several different waste management practices, including source reduction; however, the current version does not include emissions from food production and distribution due to data availability. The Ministry of the Environment of Japan published guidelines for strategic environmental assessment of waste management systems, but they do not cover those areas (MOE 2007a, b, 2008, 2011). Revision of these guidelines will likely encourage more local governments to attempt source-separated collection of food waste.

Finally, it should be noted that the perception of residents and public relations are important to the promotion of food loss prevention.

\section{Conclusions}

In this study, we focused on waste reduction activities and separate collection of household food and paper waste. The results showed that the effects of food waste reduction with separate collection on GHG emissions depend on the reason for the reduction in waste. We analyzed three cases that led to reduced waste for different reasons. In the first case, preventing food loss (PrevLoss) reduced significant amounts of GHG emissions. However, reducing the moisture contents of waste (ReducDrain) resulted in a much smaller GHG reduction. Finally, home composting (ReducHcom) increased GHG emissions. Therefore, to evaluate separate collection of household food waste, waste reduction activities should be considered. Food loss prevention has larger GHG reduction effects than anaerobic digestion. Therefore, the relationship between food loss prevention and waste management policies including separate collection will be the focus of our future research.

Acknowledgments We gratefully acknowledge Dr. Stephen Moore for his valuable comments on the manuscript and the Kyoto City Environmental Policy Bureau for their generous support of this research.
Open Access This article is distributed under the terms of the Creative Commons Attribution License which permits any use, distribution, and reproduction in any medium, provided the original author(s) and the source are credited.

\section{References}

Asano A, Yanase K, Takeda H, Mitsui M (2005) Study of the food waste recycling in Yokosuka City (third phase report). Proceedings of the 16th Annual Conference of the Japan Society of Waste Management Experts, Sendai (Japan), October 31-November 2, $2005,1: 484-486$ (in Japanese)

Cleary J (2010) The incorporation of waste prevention activities into life cycle assessments of municipal solid waste management systems: methodological issues. Int J Life Cycle Assess 15 (6):579-589

Cuellar AD, Webber ME (2010) Wasted food, wasted energy the embedded energy in food waste in the United States. Environ Sci Technol 44:6464-6469

Davis J, Sonesson U (2008) Life cycle assessment of integrated food chains - a Swedish case study of two chicken meals. Int J Life Cycle Assess 13:574-584

European Commission (2008) Green paper on the management of biowaste in the European Union, COM (2008) 811 final, Brussels, 3.12.2008

European Commission (2010) Assessment of the options to improve the management of bio-waste in the European Union:1-237

Eriksson O, Reich MC, Frostell B, Björklund A, Assefa G, Sundqvist JO, Granath J, Baky A, Thyselius L (2005) Municipal solid waste management from a systems perspective. J Clean Prod $13: 241-252$

Fukushima K, Onoue Y, Nagao N, Niwa C, Toda T (2008) Life cycle assessment of anaerobic and aerobic biological treatment process for organic waste treatment. The 8th International Conference on EcoBalance, Tokyo (Japan), December 10-12, 2008,P-039

GIO National Institute for Environmental Studies (NIES), Japan (2011) The GHGs emissions data of Japan (1990-2009). http://www-gio. nies.go.jp/aboutghg/nir/nir-e.html. Accessed September 18, 2011

Hirose Y (1995) Social psychology for environment and consumption. Nagoya University Press, Nagoya

Inaba R, Nansai K, Fujii M, Hashimoto S (2010) Hybrid life-cycle assessment (LCA) of $\mathrm{CO}_{2}$ emission alternatives for household food wastes in Japan. Waste Manage Res 28(6):496-507

IPCC (2007) Climate change 2007 (AR4), Working group I report. The physical science basis

Kim MH, Kim JW (2010) Comparison through a LCA evaluation analysis of food waste disposal options from the perspective of global warming and resource recovery. Sci Total Environ 408 (19):3998-4006

Kinnaman TC, Fullerton D (2000) Garbage and recycling with endogenous local policy. J Urban Econ 48(3):419-442

Kyoto City Environmental Policy Bureau (2009a) Survey of detailed household waste composition in Kyoto FY2008 (in Japanese)

Kyoto City Environmental Policy Bureau (2009b) Operation summary of environmental policy bureau FY2009 (in Japanese). http:// www.city.kyoto.lg.jp/kankyo/page/0000072597.html. Accessed December 11, 2010

Matsuda T, Yano J, Hirai Y, Sakai S, Yamada K, Ogiuchi M, Hori H (2010a) Life cycle analysis of household waste management considering trade-off between food waste reduction and recycling. J Life Cycle Ass Japan 6(4):280-287 (in Japanese)

Matsuda T, Yano J, Hirai Y, Yamada K, Ogiuchi M, Hori H, Sakai S (2010b) Life cycle inventory analysis on biogasification of 
household food and paper waste. 9th International conference on ecobalance, Tokyo (Japan), December 9-12, 2010, pp D1-1610

Matsuto T, Tanaka N, Habara H (2001) Computer modeling to assess cost, energy consumption and carbon dioxide emission in zero emission scenario of municipal solid waste. 12th Jpn Soc Waste Manage Exp, pp 134-146

Ministry of the Environment (MOE), Japan (2007a) Guidelines for introducing strategic environmental assessment

Ministry of the Environment (MOE), Japan (2007b) Guidelines on municipal solid waste management systems toward a sound material-cycle society for local governments

Ministry of the Environment (MOE), Japan (2008) Survey of the municipal waste treatment FY2008 (in Japanese). http://www. env.go.jp/recycle/waste_tech/ippan/h20/index.html. Accessed December 11, 2010

Ministry of the Environment (MOE), Japan (2011) Environmental statistics 2011 (in Japanese). http://www.env.go.jp/doc/toukei/ index.html. Accessed September 18, 2011

Miranda ML, Aldy JE (1998) Unit pricing of residential municipal solid waste: lessons from nine case study communities. J Environ Manage 52(1):79-93

Murata M (2000) Life cycle assessment for food waste recycling and management (in Japanese). Kyoto University master's thesis

NIES, Japan (2006) Technical development report of hydrogen production from biomass and biowaste in FY2005 (in Japanese). NIES, Tsukuba, pp 7.193

NIES, Japan (2008) Technical development report of hydrogen production from biomass and biowaste in FY2007 (in Japanese). NIES, Tsukuba, pp 7.44-7.63
Sakai S, Hirai Y, Yoshikawa K, Deguchi S (2005) Distribution of potential biomass/waste resource and GHG emission analysis for food waste recycling systems (in Japanese). J Japan Soc Waste Manage Experts 16(2):173-187

Sharp V, Giorgi S, Wilson DC (2010) Methods to monitor and evaluate household waste prevention. Waste Manage Res 28(3):269-280

Sonesson U, Björklund A, Carlsson M, Dalemo M (2000) Environmental and economic analysis of management systems for biodegradable waste. Resour Conserv Recy 28:29-53

Tabata T, Ihara T, Nakazawa H, Genchi Y (2009) Evaluating the selfdisposal of household waste in regional towns and cities: Present situation and analysis of environmental and economic effects. J Jpn Soc Mater Cycles Waste Manage 20(2):99-110 (in Japanese)

Takuma (2005) The development of efficient energy and material recovery technology by dry methane fermentation. Grants for development of future waste treatment technology (in Japanese). Technical report, pp 1-29

Tatara M, Kitajima Y, Kikuchi S, Yoshimura Y, Maeda H, Okabe M, Miyano H, Kuramochi K, Murayama H, Endoh T (2010) Development of a biogasification system for unsorted domestic combustible waste (in Japanese). Kajima Tech Res Inst Annu Rep 58:121-126

US EPA (2010) Waste reduction model (WARM) http://www.epa.gov/ climatechange/wycd/waste/calculators/Warm_home.html. Accessed September 27, 2011

Usui T (2008) Estimating the effect of unit-based pricing in the presence of sample selection bias under Japanese recycling law. Ecol Econ 66(2-3):282-288

WRAP (2009) Household Food and Drink Waste in the UK, http:// www.wrap.org.uk/retail_supply_chain/research_tools/research/ report_household.html. Accessed December 11, 2010 